\title{
A Faculty Development Program to Promote Engaged Classroom Dialogue: The Oral Communication Institute
}

\author{
Kim M. Mooney \\ Traci Fordham \\ Valerie D. Lehr
}

St. Lawrence University

The St. Lawrence University faculty development program in oral communication promotes and enhances teaching strategies and philosophies for productive and civil classroom discourse. Started in January 2002, the Oral Communication Institute $(O C I)$ provides a sustained forum in which faculty explore the relationship among oral communication, critical thinking, and deep learning. In addition to creating discourse communities, the $O C I$ affords participants opportunities to develop strategies for interactive, reflective student learning. This chapter addresses the essential components for developing an oral communication institute: clear teaching and learning goals, a deliberate format and curriculum, experiential pedagogy, and opportunities for faculty dialogue and reflection.

\section{INTRODUCTION}

A mong the majority of St. Lawrence University faculty, class discussions Arepresent a preferred pedagogical strategy for enhancing students' critical reflections on readings, performances, and presentations. However, faculty freely acknowledge that creating and sustaining substantive classroom discussions present enduring challenges. On some days, a class may be highly interactive, but the next day students respond very little to a professor's questions 
and prompts. In other classes, a few students may dominate a conversation and silence other students, speaking not to learn per se, but to assert their deeply held convictions. In almost all classes, students stop taking notes as soon as the instructor stops speaking and a classmate starts. Sometimes this response seems to represent an effort to listen, but more often, it seems to be based on a belief that knowledge comes from instructors, not peers.

Research suggests that when students arrive at college, their preconceived understanding of what constitutes good discussion does not promote classroom interactions that result in productive learning encounters, particularly between people who initially disagree with each other (Shachtman, 1995; Tannen, 1998). Extensive survey data from our own students on the National Survey of Student Engagement (NSSE, 2001) support other research findings that students are inclined to view discussion as most attractive when those involved know that others agreed with them right at the conversation's outset (Trosset, 1998). On a small, residential campus like St. Lawrence, we know that to ask students to take classroom discussion seriously is to ask that they put themselves at risk: The peers with whom they live, study, and socially interact would know what they really think about issues even if their perspectives are not neatly aligned with those of their classmates or friends.

Historical and recent evidence from St. Lawrence faculty and student data indicated a pressing need for greater faculty development efforts focused on classroom discussion pedagogies. First, the development of students' writing and oral communication skills is stated as specific and mandatory teaching and learning objectives within our First-Year Program (FYP), a required, yearlong residential living and learning community. Since its inception in the late 1980s, the FYP's faculty development efforts have focused far more on the student writing objectives even though the program's goals weigh the development of students' writing and oral communication skills equally. Second, the results from a 2001 faculty development and teaching committee survey indicated improving classroom discussions as the reaching issue of greatest interest to the faculty. Finally, results from the NSSE (2001) indicated "working with classmates on assignments outside of class" as the best single predictor for St. Lawrence students having conversations with others whom they define as different from themselves with respect to social and political backgrounds. This NSSE finding was a clear signal that the ways in which faculty organize and conceive of student discussion and dialogue can, in fact, have a significant impact on the likelihood of students engaging in productive conversations with each other both in and out of the classroom. 
According to Mintz (1999), effective, holistic faculty development programs are those that are undertaken by both the institution and the faculty. Such programs acknowledge that teaching occurs within the context of values of the institution and are not only about improving the quality of teaching but about connecting classroom work to our understanding of the organization's faculty and student cultures. As a liberal arts institution, a central goal of St. Lawrence Universiry is to foster the critical thinking skills that will prepare our students for life as responsible, contributing citizens. The university's goal statement includes as an aim that we encourage students to develop "a respect for differing opinions and for free discussion of these opinions; and an ability to use information logically and to evaluate alternative points of view." This aim echoes Baldwin's (1998) contention that college classrooms are critical places to promote civil and intellectually rigorous discussions to empower and prepare students for global citizenship.

In our then respective positions of associate dean for faculty affairs and associate dean for the first-year program, we (Kim and Val) began meeting with a small group of faculty from a number of disciplines including history, sociology, and speech and theater, who were interested in questions of civic engagement and classroom dialogue. Through our small group conversations and the support of the Center for Teaching and Learning, we submitted a proposal to the William and Flora Hewlett Foundation to support the development of a yearlong series of interconnected seminars and workshops, the Oral Communication Institute (OCI). The Hewlett Liberal Arts Program funding allowed us the time and opportunity necessary to think and talk collectively about the complex student communication and learning issues that we had identified. The primary objective of the $\mathrm{OCI}$ is not simply to convey the mechanics of developing strategies for good classroom discussions, but to promote a deeper understanding among faculty of the communication context in which those discussions will thrive.

To date, at the end of the second year of the $\mathrm{OCI}, 40$ faculty members from 14 academic departments have participated. While the majority of participants have come from the ranks of assistant and associate professors, six full professors participated in this program.

\section{The Goals of the Oral Communication Institute}

\section{Epistemology and the Teaching Process}

Starting with an intensive three-day seminar during the annual January break and continuing with follow-up meetings in the spring and again in the fall of the next academic year, the $\mathrm{OCl}$ is intentionally structured to give faculty 
uninterrupted, quality time together. Because all participants prepare in advance for the institute by reading assigned texts, they arrive for the meetings with broad, and in many cases, new backgrounds in communication theories.

Generally, most educators believe that getring students to talk in class is a good thing but often cannot say why oral communication might be important to learning. Students themselves often view class or group discussions as evidence that the professor was not prepared to "teach" that day. Some of the problems we encounter in class, when students talk but do not seem to say much, or do not seem commitred to communicating well with one another, come from our often hazy understandings of why we want them to talk in the first place. Why, indeed, does oral communication matter to the enterprise of learning? How we answer this question inevitably guides our pedagogies.

The most common faculty misconception prior to the start of the $\mathrm{OCI}$ is that it is designed to teach faculty how do design and grade students' speeches and oral presentations. While the formal and structured presentation is certainly a specific context of communication in the classroom and is addressed during the $\mathrm{OCI}$, formal and informal assignment design is not the primary goal of the OCI. The goals for the institute focus on cultivating in faculty participants a deeper understanding of communication processes and the central roles oral communication plays in the creation and dissemination of knowledge. The underlying premise of the $\mathrm{OCI}$ is that both the articulation of one's thoughts and the careful listening to the ideas and opinions of others helps us to learn more profoundly.

Deepening faculty understanding of the complex process of communication. Effective speaking and listening increase the likelihood that what one comes to know during dialogue will be more sophisticated and multilayered, regardless of the conversation's content. Giving voice to knowledge, sharing that voice with others, listening to diverse perspectives, and modifying one's thinking are crucial learning processes and critical life skills. This philosophical assumption has shaped the ways in which we construct pedagogies for the OCI.

During the institure, faculty participants begin to develop a more holistic view of oral communication in their classes and reflect on what it means to be rhetorically sensitive, or more aware of the complexity of human communication (Hart \& Burks, 1972). We, as leaders and facilitators, encourage faculty to talk about factors that are in play in college students' learning environments and how they as teachers might adapt their approaches to different classroom contexts and audiences. Once we begin discussion of how communication is essential to our classroom environments, and not simply a part of them, we are 
able to move beyond faculty's seeming need to learn how to "teach oral presentations" and onto more sophisticated discussions about oral communication in the classroom.

Educating faculty on the context of students' communication styles. Students come to our courses with myriad social positions and orientations and with many ways of thinking about and applying communication strategies. To be unaware or insensitive to the factors that influence students' communication styles and preferences is to risk not reaching them. If one of our objectives as teachers is to understand why students might be reticent to talk in class or why they do not communicate well (e.g., argue instead of listen and discuss), and to create more productive environments for learning, it behooves us to think more critically about students' roles in our classroom environment. To this end, OCI faculty participants discuss with each other the ways in which they would characterize their classrooms as communication environments. We ask them to think about the various subject positions that students have and how those social identiries might influence the ways in which students communicate in the classroom.

OCI faculty also explore both the social and institutional obstacles that might impinge upon effective classroom dialogue. For this particular portion of the institute, faculty reflect on Tannen's (1998) The Argument Culture and talk about the many social, cultural, historical, and institutional challenges to effective dialogue and discussion.

Prompting faculty to be more self-reflective about their own communication. Through their interactions with students, faculty co-create classroom norms, expectations, and ways of thinking and behaving. An important goal in the $\mathrm{OCl}$ is to assist faculty in becoming more aware of their own communication styles and to begin evaluating how their communication in the classroom contributes to their students' learning and to the classroom environment as a whole. Time is allotted during early $\mathrm{OCI}$ meetings for faculty to analyze, write, and talk about their own classroom communication style.

Assisting faculty in the development and design of their course. Through their participation in the institute, $\mathrm{OCl}$ faculty are given numerous opportunities to collaborate with each other as they develop skills and design assignments that will help them create more interactive learning experiences for students. Faculty are encouraged to be mindful of providing environments that will encourage student confidence and competence in extemporaneous and deliberate discourse, especially when that discourse involves controversial or emotionally charged topics. 


\section{The OCI Format and Curriculum}

The OCI was designed to create opportunities for faculty to engage in meaningful dialogue and experiential learning with each other. As planning for the institute got underway, it became clear that initial contact about the OCI would best be presented to the faculty as a comprehensive course with a number of basic elements.

- The announcement of the institute provided a course description.

- An application process served as course registration.

- Stated regular meeting times established an institute schedule.

- A syllabus and common reading materials were included.

- Each seminar meeting was co-facilitated or team-taught.

- Each meeting entailed some individual, small group, and plenary work.

- A reflection paper was due at the end of the institute.

In its current format, the sequencing of the $\mathrm{OCI}$ work occurs in four distinct phases: the call for participation and preparation for the meetings; the January seminar; the spring workshops; and the fall follow-through and reflection work.

All documents mentioned in this chapter that do not appear in an appendix can be found at the St. Lawrence University Center for Teaching and Learning web site at http://www.stlawu.edu/ctl/oci.hem.

\section{Soliciting Faculty Participation}

In the early fall, all faculty receive a letter describing the $\mathrm{OCI}$ goals and format. An application form is attached to the letter and interested faculty are asked to submit the form so that as facilitators, we gain a sense of faculty teaching goals and the types of courses in which faculty hope to incorporate oral communication pedagogies. With only 20 available seats each year, priority is given to continuing faculty members.

In order to expect faculty members to commit to a yearlong series of meetings and readings, a stipend equivalent to a course overload is offered. Five weeks in advance of the meetings, participants receive reading materials (see Appendix 14.1) and a syllabus (see Appendix 14.2). 


\section{The January Seminar}

The first phase of the yearlong OCI commitment begins with an intensive, three-day seminar during the winter break before spring semester classes begin. Each morning and afternoon is conceptualized as a distinct session, with guiding questions and relevant readings assigned for each day.

Day one. Our primary goal the first day is to ask faculty to consider why they wish to make dialogue and discussion central to their courses and how this desire may be related to the epistemological goals they have for their classes. That is, if a primary course goal is to lead students to definitive conclusions, how will the use of dialogue enhance the course? Alternatively, if a primary course goal is to encourage students to explore values and beliefs, how will dialogue contribute? In what ways do different forms of dialogue contribute to these epistemological objectives? We then ask faculty to discuss inquiry-based pedagogies and how they might extend their perspectives on the role of dialogue.

Day two. On the second day, we begin to discuss some of the obstacles to engaged dialogue that we see in our classrooms. This discussion covers issues ranging from how the limited racial and ethnic diversity of St. Lawrence affects student dialogue in the classroom to how the argument culture (Tannen, 1998) is apparent in the ways in which students interact with one another. We consider how our pedagogies can take such influences into account and discuss the necessity of working with students to help them to become more attentive listeners.

Day three. On the third day, we ask faculty to consider the connections between their goals for oral communication and their goals for writing assignments. The purpose is to address the ways that the speaking and writing can be reinforcing learning tools, even while recognizing the differences between the two forms of expression.

As a final opportunity to talk with one another in some detail about a particular course, we ask faculty to bring a copy of the syllabus for the course(s) they intend to modify as a result of their OCI work. They are grouped with a few other participants to work through a series of questions asking how they might try to create a different environment in the classroom to encourage student communication, how they might build dialogue into their courses, and how, or if, they might need to modify some content coverage in order to use dialogue and discussion to foster deeper understanding.

\section{January Pedagogy}

Throughout the January seminar, we use pedagogies that illustrate and suggest what faculty might want to do in their classrooms. Thus, each seminar session 
combines paired, triadic, or small-group conversations, and also includes large-group discussions. When in smaller groups, the participants are given carefully designed questions intended to help the group connect its own experiences with the readings. Examples of the types of questions asked of participants appear throughout this section and in Appendix 14.2. As facilitators, we use the small-group time to convene ourselves and modify the day's plans in order to best respond to emerging issues and requests. A final, important goal of the January seminar pedagogy is to build a discourse community. That is, this community of faculty has begun to develop a shared understanding of student communication issues. We believe this mutual knowledge contributes to the success of the OCI because it illustrates so powerfully the extent to which collaborative, engaged dialogue contributes to learning. At the end of the January seminar, an $\mathrm{OCl}$ listserv is created to further facilitate $\mathrm{OCI}$ faculty communication between meetings.

\section{Spring Workshops}

As announced in advance of the institute, $\mathrm{OCl}$ participants are scheduled to meet four times during the spring semester. These meetings afford opportunities to expand the sense of community created in January and to address specific classroom issues that emerge from the January conversations. The four spring meetings draw on various local experts from either the $\mathrm{OCI}$ group or the St. Lawrence faculty at large to lead discussion or hands-on workshops on issues that all participants have agreed at the end of January would be helpful and interesting.

After both January seminars in 2002 and 2003, it was clear that faculty were interested in exploring the role of technology in classroom discussions. They wanted to talk more about the ways in which technology may be used both in and out of class to create richer dialogues in the classroom. In both years, $\mathrm{OCI}$ participants agreed to demonstrate for the group how they utilize online discussion assignments to initiate and enrich student-to-student conversations both inside and out of the classroom. The group then discussed the merits and drawbacks of online dialogue as an impetus for more fruitful inclass dialogue. The other post-January workshop suggestions were similar for each year and covered the design and grading of formal student oral presentations, the use of creative role-play and other theater exercises to engage even the most reticent students, and a panel of $\mathrm{OCl}$ participants reporting on the efficacy of their pedagogical attempts. 


\section{Fall Reflection}

Throughout the January and spring meetings, the substance of the $\mathrm{OCl}$ sessions is focused on specific classroom dialogue and discussion issues as identified by the participating OCI faculty and as presented in the assigned readings. The pedagogy of the January and spring meetings is experiential in nature so the OCI faculty can apply and practice both new and familiar approaches to generating and sustaining classroom discussions. In the fall, the number of plenary meetings is substantially reduced and faculty are asked instead to begin to work more directly with one another in dyads or in small groups rather than as a larger collective.

The reasons behind the pedagogical shift are both logistical and philosophical. We are concerned that to continue the expectation of regular group meetings after changing to a fall schedule would create numerous conflicts that would cause us to lose participants along the way to committee and other standing obligations. The second, more strongly held conviction had to do with the underlying premise of the $\mathrm{OCI}$. Ongoing faculty-to-faculty interaction is a crucial and desirable learning tool for all $\mathrm{OCI}$ participants. If we believe fostering more engaged communication between students will develop an understanding of how much they can learn from each other, the same conviction must hold true for faculty.

Once the fall semester is underway, the $\mathrm{OCI}$ group meets in a plenary session, which has two primary functions: to review and refresh the themes from the spring meetings and to disseminate the two primary assignments for the fall, both of which are described below.

Peer partner program. Each $\mathrm{OCI}$ participant is paired with another $\mathrm{OCI}$ faculty member outside of his or her discipline or department. The partnerships are envisioned on a number of potential levels but never on an evaluative one. At a minimum, the partners complete reflective conversation worksheets that pose questions to encourage them to engage in conversations that contextualize their respective teaching and learning philosophies. The questions also promote clarification of their goals around the role of oral communication strategies and assignments in a designated course. When introducing the peer partner program to the OCI faculty, the exchange of classroom visits is discussed as an ideal follow-through to the reflective conversation worksheets and feedback conversations. Although the class visits are optional, there is a clear expectation that if peer partners decide to take this route, they will review best practices in collegial classroom visits as described in Chism's (1999) resource book on peer review. The circumstances under which partners meet and the frequency of the meetings are determined by each partnership. 
Reflective writing assignment. The final $\mathrm{OCI}$ assignment involves submitting a paper at the end of the fall semester. The writing assignment attempts to connect the peer partner dialogue work and OCI participants' own teaching and learning philosophy and practices. In their writing, faculty reflect on the substance and process through which they worked when completing the reflective conversation worksheet on their own and to explain how conversations with a peer partner crystallized their thinking and influenced their decisions about using oral communication strategies in class. Finally, the writing assignment asks the faculty to reflect on their participation in the $\mathrm{OCI}$, and to comment on how critically engaged conversations with colleagues about pedagogy affected their own teaching and learning experiences.

A final OCI plenary meeting is held in mid-December, after submitting their papers. The group comes back together to talk about their responses and perhaps draw parallels between the usefulness of their dialogues with their colleagues and the powerful potential for student learning through dialogues with their peers.

\section{FACULty Response to the OCI}

The formal survey instrument discussed below offers affirmative documentation of faculty members' reasons for why they want to create more oral communication opportunities for their students, but our observations of and interactions with $\mathrm{OCI}$ participants also informed us of the program's success. At the end of each seminar day in January, faculty members would leave the Center for Teaching and Learning to go to their offices to work on a new assignment or to revise a syllabus based on an activity or conversation from that day's $\mathrm{OCI}$ session. The faculty participants did not wait a semester as originally planned to implement their new goals; they were revising their syllabi for courses that were scheduled to start in three days. Nor did the $\mathrm{OCI}$ participants limit their efforts to the one course they had identified as their "OCI course"; their oral communication goals for students were integrated into their other spring semester courses as well. The faculty engagement and excitement throughout the January meetings continued throughout the semester and generated tremendous faculty interest across campus.

After $20 \mathrm{St}$. Lawrence faculty members participated in the inaugural $\mathrm{OCI}$, the Center for Teaching and Learning sponsored a pancl presentation for members in this first group to talk about their perspectives on the institute and the impact on their classroom teaching. Over 25 colleagues from all over campus who had not participated in the OCI attended the presentation. This faculty 
development program had captured the faculty's interest; the following week we received over 20 applications for the second year.

The OCI faculty response has been powerful and positive, though not without helpful criticisms. The selective comments below capture the general consensus expressed through email correspondence with OCI participants after the first January seminar in 2002. Because there was consensus on what strategies worked and what strategies needed work, as facilitators, we were provided with a strong sense of the format, curricular, and pedagogical elements to maintain or retool for the next year.

\section{Favorable OCI Elements Expressed in the Survey}

- What I learned at the OCI was to ask what I expected out of class discussions. Why was it useful to have them? I came away from the OCI with an understanding that much like writing, talking something out is a process by which we think through an issue or an idea.

- Before the three-day workshop began, the readings began to reshape my thoughts about how we listen and engage in dialogue as well as how we speak.

- I found lots of great, pragmatic ideas for some useful transformations in my classes and was given the time and context for serious, critical reflecting about my pedagogy and teaching philosophy.

- The most valuable thing for me was simply the conversations with colleagues (both small groups or pairs) and hearing about the kinds of classroom situations they encounter and things they have tried and whether they worked well.

\section{OCI Elements Requiring Improvement}

- The amount of theoretical reading was too great and did not provide enough discussion to warrant the quantity.

- The use of jargon and references to unfamiliar authors by some participants confused faculty from different disciplines.

\section{Faculty Reflections on their Goals and Rationales}

On the first and last days of the 2003 January seminar, $\mathrm{OCl}$ faculty completed a questionnaire which included the item, "What are your rationales and goals for incorporating oral communication by students into your course(s)?" On 
the pre-institute survey, the most frequently cited rationale for incorporating oral communication opportunities in classes was the general belief that students learn better when they are actively engaged with the material. Faculty listed a variety of goals for incorporating oral communication in their course(s), most often citing the desire to get students to take responsibility for their own learning, to enhance oral communication skills, and to help students "engage over differences" (i.e., to be more respectful of each other and think to about diverse viewpoints).

In the post-institute survey, $\mathrm{OCI}$ faculty generated more goals per person than they did for the pre-institute one. Many themes carried over from pre-institute to post-institute assessment, but in the post-institute survey, many OCI participants made greater connections between using more dialoguecentered pedagogies in the: courses and improving students' critical thinking. The post-institute commentary confirms the level of engagement with and commitment to the numerous ideas and teaching applications shared over the course of the three-day seminar.

\section{ThE FUTURE OF THE OCI}

In January 2004, we arrived at the end of the Hewlett Foundation funding and our capacity to offer hefty stipends to $\mathrm{OCI}$ participants for a full-year institute. We did use the remaining grant funds to offer a modified institute for interested $\mathrm{OCI}$ faculty alumni. The two-day agenda was designed to help faculty participants renew their thinking and share their best practices related to oral communication in teaching and learning. We also introduced the group to deliberative and sustained dialogue techniques to foster conversations about possible applications for these types of group dialogues in the broader campus community. Through our work with the $\mathrm{OCI}$, we have become involved with the St. Lawrence University Journey Towards Democracy dialogue project sponsored by the Association of American Colleges and Universities (http://www.aacu-edu.org/civic_engagement/projects.cfin) and are beginning to design ways in which the two programs may combine efforts to create a whole new set of workshops on dialogue-centered pedagogies for interested faculty.

Based on the success of the $\mathrm{OCl}$, we believe that we have cultivated the foundation for an institutional commitment to oral communication across the curriculum. The three of us are involved in a newly formed working group established to address the need for academic and peer-mentoring support for student oral communication skills, and to think about how this effort should be connected to already existing support for student research and writing skill 
development. Such a program would complement the progress that faculty are making through the increased integration of dialogue and discussion-centered pedagogies in their classroom teaching.

\section{ACKNOWLEDGMENTS}

The authors wish to acknowledge the generous support of the William and Flora Hewlett Foundation Liberal Arts Program without which this faculty development project would not have been fully realized. We also thank Michael Reder for his helpful suggestions on an earlier version of this manuscript.

\section{References}

Baldwin, R. G. (1998). Academic civility begins in the classroom. Essays on Teaching Excellence, 9. Retrieved May 9, 2004, from http://www.unm.edu/-castl/ Cast__Docs/Packet $/$ Academic\%20Civility\%20Begins\%20in\%20the\%20Class room.html

Chism, N. V. N. (1999). Peer review of reaching: A sourcebook. Bolton, MA: Anker.

Hart, R. P., \& Burks, D. M. (1972). Rhetorical sensitivity and social interaction. Speech Monographs, 39, 75-91.

Mintz, J. (1999, Spring). Faculty development and teaching: A holistic approach. Liberal Education, 85, 32-37.

National Survey of Student Engagement. (2001). Results from St. Lawrence University. Bloomington, IN: Indiana University. Retrieved December 1, 2003, from http://www.indiana.edu/-nsse/

Shachtman, T. (1995). The inarticulate society: Eloquence and culture in America. New York, NY: Free Press.

Tannen, D. (1998). The argument culture: Stopping America's war of words. New York, NY: Ballantine.

Trosset, C. (1998, September/October). Obstacles to open discussion and critical thinking: The Grinnell College study. Change, 30(5), 44-49. 


\section{APPENDIX 14.1}

\section{St. LaWrence University Oral Communication Institute}

\section{Reading List for Year II}

Burbules, N. C. (1993). Dialogue in teaching: Theory and practice. New York, NY: Teacher's College Press.

Burbules, N. C., \& Rice, S. (1991). Dialogue across differences: Continuing the conversation. Harvard Educational Review, 61, 393-416.

Cary, L. (1991). Black ice. New York, NY: Vintage.

Finkel, D. (2000). Teaching with your mouth shut. Portsmouth, NH: Boynton $\&$ Cook.

Garrison, J. W., \& Kimball, S. L. (1993). Dialoguing across differences: Three hidden barriers. Retrieved May 9, 2004, from http://www.ed.uiuc.edu/ EPS/PES-Yearbook/93_docs/GAR_KIMB.htm

Tannen, D. (1998). The argument culture: Stopping America's war of words. New York, NY: Ballantine.

Tatum, B. (1992). Talking about race, learning about racism: The application of racial identity development theory in the classroom. Harvard Educational Review, 62, 1-24.

Trenholm, S. (1999). Thinking through communication: An introduction to the study of human communication (Chapter 3., 3rd ed.). Boston, MA: Allyn and Bacon. 


\section{APPendix 14.2}

\section{ST. LaWrence University OCI Annotated January Syllabus}

\section{Monday January 13, 2003: Morning}

Question: What are our goals in cultivating productive dialogue in our classes?

- We ask participants to think about how they currently conceptualize and use oral communication in their classrooms.

- In small groups, $\mathrm{OCI}$ faculty discuss classrooms as communication environments by talking about the identities that people bring to the classroom and how these factors influence learning.

\section{Monday, January 13, 2003: Afternoon}

Question: How are different discourse strategies useful in relation to different epistemological assumptions?

- Participants talk in small groups about the readings to consider how different authors conceptualize dialogic-centered pedagogies and whether these ideas make sense given the particular realities on our campus.

- Participants then discuss the epistemological foundation of their courses and this affects their use of dialogue.

Relevant readings: Finkel; Burbules, Chapters $5 \&$ 6, Dialogue in Education

\section{Tuesday, January 14, 2002: Morning}

Question: What factors make communication and dialogue more complex?

- We talk in small groups and as a large group about how issues of diversity/marginality affect discourse at St. Lawrence.

Relevant readings: Cary

\section{Tuesday, January 14, 2003: Afternoon}

Question: What are obstacles to engaged dialogue in the classroom?

- In plenary, the group discusses the readings in order to identify factors that interfere with engaged dialogue, including the limitations to effective listening. The discussion is then directed to how we might overcome some of these obstacles. 
Relevant readings: Garrison \& Kimball; Tannen; Tatum; Trenholm

Wednesday, January 15, 2003: Morning (with the writing program director) Question: How might writing and oral communication complement one another in our courses?

- The group discusses the ways in which writing and speaking have similar and different expressive properties and how we might design pedagogies that use writing and speaking in complementary ways.

\section{Wednesday, January 15, 2003: Afternoon}

Question: What changes might we make to syllabi in order to better foster our communication goals? All participants bring syllabi to this session.

- In pairs, faculty talk about the specific course each plans to modify as a result of their $\mathrm{OCl}$ work. 